OPEN ACCESS

Edited by:

Chris J. Gibbons,

The University of Manchester, UK

Reviewed by:

Richard S. John,

University of Southern California, USA

Mingna Liu,

Northwestern University, USA

*Correspondence:

Anke Köbach

anke.koebach@uni-konstanz.de

Specialty section:

This article was submitted to Psychology for Clinical Settings, a section of the journal Frontiers in Psychology

Received: 19 December 2014 Accepted: 02 November 2015 Published: 08 December 2015

Citation:

Köbach A, Nandi C, Crombach A, Bambonyé $M$, Westner $B$ and Elbert $T$ (2015) Violent Offending Promotes

Appetitive Aggression Rather than Posttraumatic Stress - A Replication Study with Burundian Ex-Combatants. Front. Psychol. 6:1755. doi: 10.3389/fpsyg.2015.01755

\section{Violent Offending Promotes Appetitive Aggression Rather than Posttraumatic Stress-A Replication Study with Burundian Ex-Combatants}

\author{
Anke Köbach ${ }^{1,2 \star}$, Corina Nandi ${ }^{1}$, Anselm Crombach ${ }^{1,2,3}$, Manassé Bambonyé ${ }^{3}$, \\ Britta Westner ${ }^{1}$ and Thomas Elbert ${ }^{1,2,3}$ \\ ${ }^{1}$ Clinical and Neuropsychology Group, Department of Psychology, University of Konstanz, Konstanz, Germany, ${ }^{2}$ Vivo \\ International, Konstanz, Germany, ${ }^{3}$ Department of Clinical Psychology, Université Lumière de Bujumbura, Bujumbura, \\ Burundi
}

Research has identified appetitive aggression, i.e., the perception of committed, violent acts as appealing, exciting and fascinating, as a common phenomenon within populations living in precarious and violent circumstances. Investigating demobilized soldiers in the Democratic Republic of Congo (DRC) demonstrated that violent offending is associated with appetitive aggression and not necessarily with symptoms of posttraumatic stress. In the present study, we sought to replicate these results in an independent and larger sample of demobilized soldiers from Burundi. As with the Congolese ex-combatants, random forest regression revealed that the number of lifetime perpetrated violent acts is the most important predictor of appetitive aggression and the number of lifetime experienced traumatic events is the main predictor for posttraumatic stress. Perpetrated violent acts with salient cues of hunting (pursuing the victim, the sight of blood, etc.) were most predictive for perceiving violent cues appealingly after demobilization. Moreover, the association of violent acts and appetitive aggression as well as traumatic events and posttraumatic stress remains strong even years after demobilization. Patterns of traumatic events and perpetrated acts as predictors for posttraumatic stress and appetitive aggression seem to be robust among different samples of ex-combatants who fought in civil wars. Psychotherapeutic interventions that address these complementary facets of combat-related disorders - namely, posttraumatic stress and appetitive aggression - are indispensable for a successful reintegration of those who fought in armed conflicts and to achieve a successful transition to peace.

Keywords: ex-combatant, soldier, demobilization, DDR, DRC, aggression, PTSD, violence

\section{INTRODUCTION}

Combatants who fight in the current civil wars are exposed to numerous forms of extreme violence. They often witness, experience and also perpetrate acts like killing, torture, rape, and other violent attacks. The exposure to combat has consistently been associated with heightened risks for posttraumatic stress disorder (PTSD; Dohrenwend et al., 2006; Hoge et al., 2006; Odenwald et al., 2009; Schaal et al., 2012; Priebe et al., 2013). In the dynamics of scientific research, PTSD is 
widely considered as disorder of memory where sensory, interoceptive, cognitive, and emotional cues associated with the traumatic event(s) are highly cohesive and insufficiently innervated by contextual information (Ehlers and Clark, 2000; Brewin et al., 2010; Schauer et al., 2011; Elbert et al., 2015). Therefore, anchoring traumatic cues into autobiographic structures using exposure techniques had been proven highly effective during the last decades (Powers et al., 2010; Robjant and Fazel, 2010; Elbert et al., 2015). Recent literature however demonstrated that these interventions were less effective in veteran populations (Steenkamp and Litz, 2013) and that the offender status may hamper treatment gains (Stenmark et al., 2014).

\subsection{Combat High or Traumatic Stress}

Researchers have been demonstrating that trauma symptoms in veterans are particularly prominent among those who have participated in killing, or have actively been implicated in atrocities (MacNair, 2002; Maguen et al., 2009, 2010; Komarovskaya et al., 2011; Van Winkle and Safer, 2011). Therefore, they categorized perpetration as traumatic (MacNair, 2002). Accordingly, heightened levels of aggression have been found in military personnel exposed to combat (Hecker et al., 2012; Morland et al., 2012) and in some cases, violent outbursts may be explained by the hypervigilance symptoms of posttraumatic stress disorder (Morland et al., 2012). However, perpetrating violent acts might also be perceived appealingly (Nell, 2006; Elbert et al., 2010); a concept termed appetitive aggression (Elbert et al., 2010).

\subsection{Appetitive Aggression}

Aggression is commonly defined as overt behavior that has the intention of inflicting physical harm (Anderson and Bushman, 2002). The concept covers two different subtypes: impulsivereactive and controlled-instrumental (Vitiello and Stoff, 1997; Anderson and Bushman, 2002; Nell, 2006; Elbert et al., 2010). Reactive aggression refers to all aggressive behavior that is provoked by an external trigger. In contrast, instrumental aggression is exerted to achieve a certain goal and-if the behavior was successful-is followed by a positive outcome (Vitiello and Stoff, 1997). Appetitive aggression is a subcategory of the latter; it is exerted to gain a positive feeling and thus, is intrinsically motivated. For the trait of appetitive aggression, cues associated with violent acts are perceived appealingly rather than traumatically (Elbert et al., 2010). The enjoyment of violence in men had been postulated in psychological research before; for instance, Nell (2006) described "the emotional state of the warrior in combat" as "that of predators and hunters, with high arousal, positive affect, and heightened libido (...)." In Grossman (1995) a need for aggression is defined as "combat addiction," which develops from preceding "combat highs" where the combatant was "float[ing] around, laughing, joking, having a great time, totally oblivious to the dangers around" him. Recently, Moran et al. (2014) demonstrated distinct neural circuitries for appetitive vs. reactive aggression.

Elbert et al. (2010) framed the etiological concept of appetitive aggression as an analog to the theory of $d e$-contextualized neural representations in PTSD: as perpetrated violent acts, and thus combat highs accumulate the memory develops a strong but fragmented associative collection of cues (interoceptive, sensory, cognitive, emotional) that are gathered at different points in time. As with traumatic events, context-related neural structures are assumed to be less active in combat highs, and thus implicit/hot and explicit/cold/context information will later be represented by insufficiently connected memory structures. In contrast to the trauma network, the so-called hunting network contains however a positive valence (Elbert et al., 2010, 2015).

The exposure of violence-regardless whether witnessed, experienced or perpetrated-shares a considerable number of cues (e.g., blood, suffering, screaming, knife, weapon, or heart beat), which may be associated with both trauma and/or perpetration. Therefore, the hunting and the trauma networks are linked-they do not however merge due to their opposing valence. According to the context and the current brain state, external stimuli can trigger one or the other network, and thus the corresponding cognitions, emotions, interoception, behavior and/or sensory perception. The line between posttraumatic stress and appetitive aggression blurs with each additional ambivalent cue that is associated with traumatic stress and combat high. Due to the potential domination of shared cues by the hunting network, appetitive aggression may have a preventive effect on posttraumatic stress. This had been demonstrated in various studies (e.g., Weierstall et al., 2011). This antagonistic effect seems to be constrained to patients with low to moderate PTSD symptom severity. After a certain threshold of traumatic events, even people with high appetitive aggression will succumb to PTSD (Weierstall et al., 2013a).

During the last 5 years, the concept has been validated in various countries, including Germany (Weierstall et al., 2012a), South Africa (Weierstall et al., 2013b), DRC (Hecker et al., 2012), Burundi (Crombach and Elbert, 2015), Uganda (Weierstall et al., 2012b), Rwanda (Weierstall et al., 2011), and Colombia (Weierstall et al., 2013a). In sum, the major findings demonstrate that (1) heightened levels of appetitive aggression are common in former combatants/veterans (Weierstall and Elbert, 2011), even years after their demobilization (Weierstall et al., 2012a; Nandi et al., in press), (2) a building block effect for appetitive aggression, i.e., the more types of violent acts are committed, the higher the level of appetitive aggression (Hecker et al., 2012; Crombach et al., 2013; Hermenau et al., 2013a) (see also the building block effect for posttraumatic stress; Schauer et al., 2003), (3) a heightened level of appetitive aggression has a protective impact on posttraumatic stress (Weierstall et al., 2011, 2012a,b; Hecker et al., 2013) — up to a certain threshold of PTSD symptom severity (Weierstall et al., 2013a), and (4), higher ranks in the armed group seem to be associated with a stronger tendency toward violence (Crombach et al., 2013).

\subsection{Replication}

In an attempt to account for reports of combat high and its etiology, one of our earlier studies (Köbach et al., 2014) in the eastern DRC assessed recently demobilized Congolese excombatants and found perpetrated violent acts with salient cues of hunting (e.g., attacking a village or settlement, participating in a massacre, etc.) to be the most important predictors for appetitive aggression compared to other specific events or acts. 
Furthermore, we found evidence that violent offending was significantly associated with appetitive aggression, but only weakly predictive for symptoms of posttraumatic stress (Köbach et al., 2014). Nevertheless, neither events of traumatic stress nor acts of perpetration were totally negligible for the level of appetitive aggression or posttraumatic stress.

Focusing on the overlap between victimization and perpetration, we sought to replicate the results in an independent and larger sample. To examine the association of violent acts and traumatic events with appetitive aggression and posttraumatic stress, we analyzed data from formally demobilized Burundian ex-combatants. A priori hypotheses were set out according to the major findings in DRC (Köbach et al., 2014): (1) Specific types of traumatic events and perpetrated acts (specTE/PA) and the total number of types of traumatic events, witnessed (totTE-wit), experienced (totTE-exp) and perpetrated (totPA), predict the level of appetitive aggression and posttraumatic stress. Perpetrated violence with salient cues of hunting show higher predictive importance than other events. (2) The total number of perpetrated types of violent acts (totPA) is the best predictor for appetitive aggression, while the total number of self-experienced traumatic event types (totTE-exp) is the best predictor for posttraumatic stress.

\section{MATERIALS AND METHODS}

\subsection{Participants and Procedure}

We interviewed 392 male Burundian ex-combatants, who were contacted through an official national veteran association. A total of 24 participants had to be excluded due to missing data and one because of invalid answers; the final sample $(N=367)$ had an average age of 36 years $(S D=8.5$, range: $19-62)$ and reported 7 years $(S D=3.0$, range: $0-17)$ of formal education. On average, they had been recruited by the age of 19 years $(S D=4.2$, range: $6-39)$, had spent 12 years $(S D=7.3$, range: $0-35)$ in a (para)military group and had been demobilized 5.5 years $(S D=$ 2.0, range: $0-14$ ) before we conducted the interviews.

The ethical review boards of the University of Konstanz, Germany and of the University Lumière of Bujumbura, Burundi approved this study. Participation was voluntary and participants had to sign an informed consent prior to the interview (including an explanation of confidentiality requirements in psychological research and therapy). In case of illiteracy, oral informed consents were collected. Fulfilling the highest and most secure data encryption standards, a new electronic data coding and storage procedure using tablet-PCs (iPad) ensured confidentiality. Participants received compensation equivalent to 5 Euro to cover transportation expenses.

Interviews were conducted at the campus of the University Lumière in Bujumbura and took on average $1.5 \mathrm{~h}$. Five clinical psychologists from the University of Konstanz, one clinical psychologist and six advanced students of clinical psychology from the University Lumière interviewed the participants. Interviews were carried out in Kirundi. Non-local interviewers conducted the interviews with the help of five interpreters. Before the application of the interview, all questionnaires had been translated into Kirundi using blind, back and forth translations and were intensively discussed with local experts to guarantee a precise interpretation. All interviewer and interpreters had been trained in the concepts of mental disorders and forms of aggressive behavior prior to the data collection and received continuous supervision to ensure data quality.

\subsection{Measures}

All instruments were applied as a semi-structured interview beginning with the informed consent. In the following first part of the interview, socio-demographic information was collected including age, former (para)military affiliation, age of recruitment, and the years spent in armed groups. Afterwards, exposure to violence, posttraumatic stress, and appetitive aggression were assessed (Nandi et al., in press).

\subsubsection{Exposure to Violence}

We assessed exposure to distinct types of violent and potentially traumatic events with a dichotomous (yes/no) checklist of 31 items (nine lifetime self-experienced potentially traumatic events, seven potentially traumatic childhood experiences, nine lifetime witnessed potentially traumatic events, six lifetime perpetrated violent acts; Nandi et al., in press). Aiming for consistency with the original study (Köbach et al., 2014), we excluded five events that had not been assessed in DRC (deprived of food during childhood, social exclusion during childhood, neglect during childhood, loss of caregiver during childhood, witnessing suicide). By summing up the remaining items (26 in total), we calculated the total number of witnessed traumatic event types (totTE-wit; possible range: $0-8$ ) and experienced traumatic event types (totTE-exp; possible range: $0-12$ ), and the number of types of perpetrated violent act (totPA; possible range: 06). Furthermore, we used each of the 26 specific traumatic events and perpetrated acts (specTE/PA) as predictors. Figure 1 provides an overview of the events included in the analysis of data assessed in Burundi and DRC and their incidence rates.

\subsubsection{Posttraumatic Stress}

Symptoms of PTSD were investigated using the PTSD Symptom Scale-Interview (PSS-I, Foa et al., 1993; Foa and Tolin, 2000). The PSS-I is a semi-structured interview, which consists of 17 items corresponding to the diagnostic criteria of the DSM-IV and referring to the last 4 weeks. Each item is rated on a four-point scale ranging from 0 (not at all/only once) to 3 (five or more times per week/almost always). The instrument has proven validity in comparable East-African samples (Ertl et al., 2010). In the present study Cronbach's $\alpha$ was 0.93 .

\subsubsection{Appetitive Aggression}

To assess appetitive aggression we used the Appetitive Aggression Scale (AAS; Weierstall and Elbert, 2011), a semi-structured interview that has also been used and validated in comparable populations. The AAS consists of 15 items rated on a five-point scale ranging from 0 (I totally disagree) to 4 (I totally agree). Appetitive aggression is conceptualized as trait, thus referring to a positive perception of violence (e.g., "Is it exciting for you if you make an opponent really suffer?," "Once fighting has started do you get carried away by the violence?", or "Once you got used to 


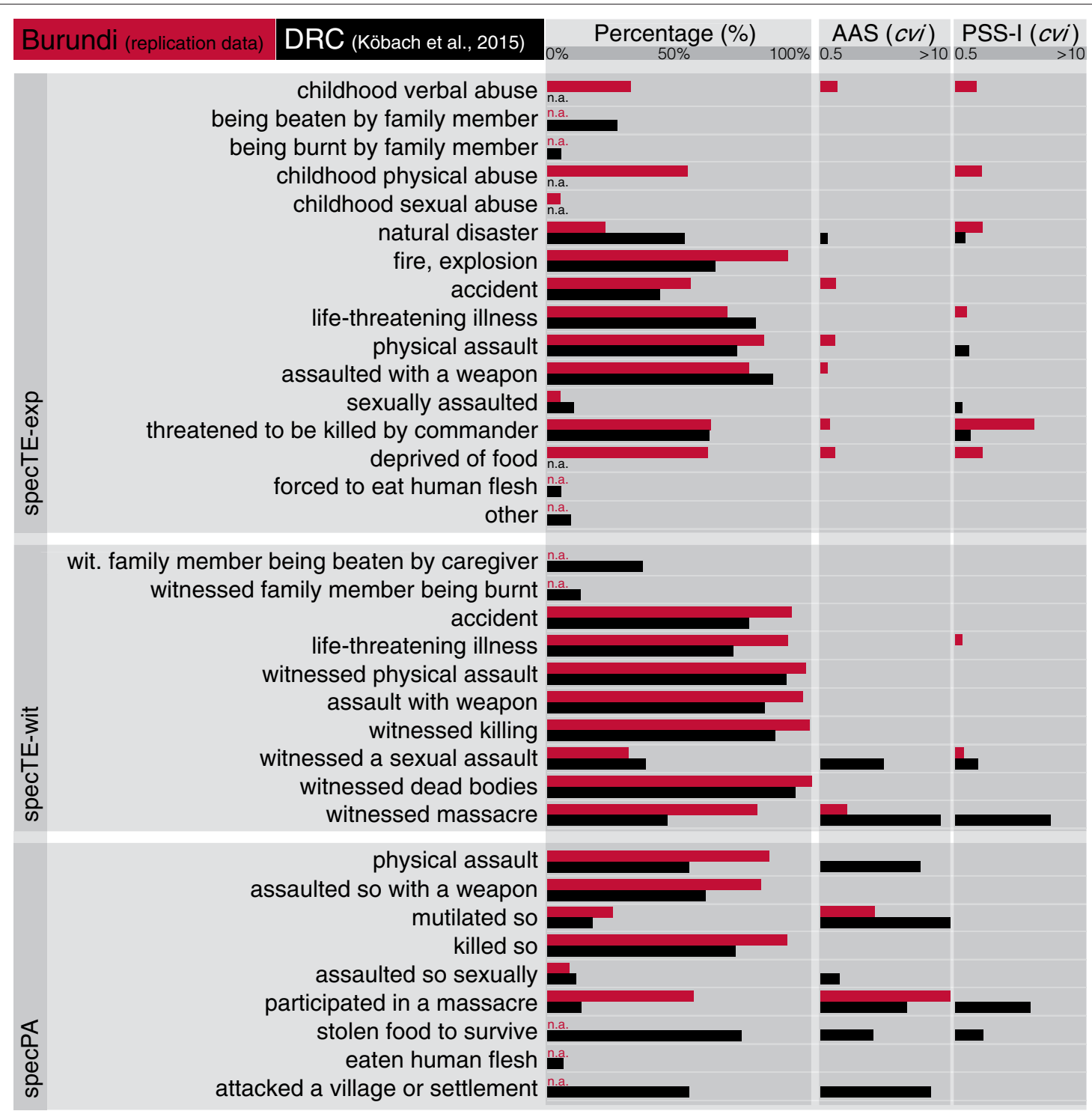

FIGURE 1 | Lifetime exposure to violence (\%) and cvis for the AAS and PSS-I sum scores resulting from ex-combatants in Burundi vs. DRC. The figure shows similar patterns of prevalence rates as well as the predictor's importances in predicting AAS and PSS-I for Burundian and Congolese ex-combatants. The cvis reveal violent acts with salient cues of hunting (e.g., participating in a massacre) to be most predictive for the AAS score. The prediction of PSS-I by participation in a massacre and stolen food to survive was not replicated. specTE-exp, specific traumatic events-experienced; specTE-wit, specific traumatic events-witnessed; specPA, specific perpetrated acts; n.a. (red), not assessed in Burundi; n.a. (black), not assessed in DRC.

being cruel, did you want to be crueller and crueller?"). In the present study Cronbach's $\alpha$ was 0.89 .

\subsection{Analysis}

As in the original study (Köbach et al., 2014), we used random forest regression with conditional inference trees (RF-CI), a non-parametric machine learning technique. Unlike the classical random forest, the RF-CI does not display a bias toward predictors with many categories in the variable selection process (Strobl et al., 2008). Following the principles of ensemble methods, a certain number of trees are aggregated to compose the random forest. Each tree is built using binary splits of the previously subsampled data (subsampling rate $=63.2 \%$; Strobl, 2008; Strobl et al., 2009a). The splitting variable is chosen according to the strength of the association between the covariates and the outcome (Hothorn et al., 2006b; Strobl et al., 2009 b) from a set of randomly preselected predictors (Grömping, 2009). Next, the importance of each predictor variable is ranked based on the ensemble of trees (conditional variable importance, cvi; Strobl et al., 2008). The goodness of fit can be assessed using the out-of-bag data (OOB). The results are used to calculate a pseudo- $R^{2}$ from the mean squared error (MSE) and the total sum of squares (SST; OOB- $R^{2}=1-\mathrm{MSE} / \mathrm{SST}$; Grömping, 2009). 
RF-CI provides an ordinal ranking of variables according to their importance for the outcome prediction (conditional variable importance, $c v i$ ), thus in this study for traumatic events and perpetrated acts in order to predict the level of appetitive aggression and posttraumatic stress. Further, the OBB- $R^{2}$ implies the fit of the model (Strobl et al., 2009b). Consequently, four models are presented in this study: (1) the AAS sum score predicted by specTE/PA (RF-CI:1, spec-model AAS $_{\text {), }}$ (2) the AAS sum score predicted by totTE-exp, totTE-wit, and totPA (RFCI:2, tot-model ${ }_{A A S}$ ), (3) The PSS-I sum score predicted by specTE/PA (RF-CI:3, spec-model ${ }_{P S S-I}$ ), (4) PSS-I sum score predicted by totTE-exp, totTE-wit, and totPA (RF-CI:4, totmodel $_{P S S-I}$ ). The analysis was conducted using $\mathrm{R}$ (version 2.15.0); the implementation we used was cforest (Hothorn et al., 2006a) from the $\mathrm{R}$ package party (Strobl et al., 2009a) with unbiased variable selection (Hothorn et al., 2006a,b, following Westner, 2013).

Furthermore, Brandt et al. (2014) recently published a "replication recipe" including crucial criteria for such endeavors. This guideline provides an efficient and standardized way to present the importance of a replication, the methods, and the results. The "36-question guide of the Replication Recipe" was applied in the present study (see Table 1 at the end of the article).

\section{RESULTS}

\subsection{Exposure to Violence}

The participants were exposed to a high range of experienced $(M=6.1, S D=2.0$, range: $0-12)$ and witnessed $(M=6.8$, $S D=1.0$, range: $2-8)$ traumatic event types, and perpetrated violent acts $(M=3.4, S D=1.4$, range: $0-6)$. Only $16(4.4 \%)$ participants reported having committed none of the perpetrated violent acts. Everyone had witnessed at least two traumatic event types, and only one participant reported not having experienced any of the traumatic events. The high variance of combat exposure is also reflected in the levels of appetitive aggression $(M=28.5, S D=14.6$, range: $0-58)$ and posttraumatic stress $(M=13.7, S D=11.2$, range: $0-42)$.

\subsection{Specific Traumatic Events and Perpetrated Acts (RF-Cl:1 and RF-Cl:3)}

Figure 1 illustrates the $c$ vis for the AAS and PSS-I sum scores in comparison with the original study. The OBB- $R^{2}$ explained $36 \%$ of variance for the AAS and 30\% for the PSS-I sum score (in the Congolese sample of the original study, 33\% of the variance was explained for the AAS and 27\% for the PSS-I sum score).

\subsection{Total Scores of Events and Acts (RF-Cl:2 and RF-Cl:4)}

The pattern of the $c v i$-values of the total scores was similar in Burundian ex-combatants, compared to Congolese excombatants. TotPA had the highest predictive value for the AAS sum score $\left(c v i_{\text {Burundi }}=28, c v i_{D R C}=88\right)$, compared to totTE$\exp \left(c v i_{\text {Burundi }}=13, c v i_{D R C}=4\right)$ and totTE-wit $\left(c v i_{\text {Burundi }}=5\right.$, $\left.c v i_{D R C}=4\right)$. TotTE-exp $\left(c v i_{\text {Burundi }}=24, c v i_{D R C}=10\right)$ had the highest impact on participants' PSS-I sum scores; totTE-wit had a minor impact $\left(c v i_{B u r u n d i} \leq 1, c v i_{D R C}=8\right)$. Essentially, the importance of the totPA in predicting the PSS-I sum score was low in both studies: $c v i_{B u r u n d i}=1$ and $c v i_{D R C}=2$. The OBB- $R^{2}$ explained $37 \%$ of the variance for the AAS sum score (RF-CI:2) and $24 \%$ for the PSS-I sum score (RF-CI:4); (in the Congolese sample, $44 \%$ of the variance was explained for the AAS and $34 \%$ for the PSS-I sum score).

\section{DISCUSSION}

In this article, we successfully replicated the most important findings presented in a previous study with Congolese excombatants. With a larger sample of Burundian ex-combatants, we showed that specific types of traumatic events and violent acts, as well as the total number of these incidents, predicted appetitive aggression and posttraumatic stress. Moreover, the total number of perpetrated violent acts (totPA) was the most important predictor for the level of appetitive aggression, while the total number of experienced traumatic event types (totTEexp) was the most important predictor for posttraumatic stress. Specific event types and violent acts with salient cues of violence had the strongest impact on the level of appetitive aggression in both samples, which thereby seems to be a robust finding. The accumulated number of violent acts and traumatic event types (tot-model ${ }_{A A S / P S S-I}$ ) was not superior in predicting the level of appetitive aggression or posttraumatic stress, in comparison to models that used specific events (spec-model AAS/PSS-I $_{\text {) }}$.

The findings in this article strengthen the evidence that perpetrated violent acts can be perceived as appealing (Elbert et al., 2010), thus not as traumatic (MacNair, 2002) and most importantly, are rather associated with appetitive aggression $\left(c v i_{\text {Burundi }}=28, c v i_{D R C}=88\right)$ than with posttraumatic stress $\left(c v i_{\text {Burundi }}=1, c v i_{D R C}=2\right.$ ). In addition, none of the specific perpetrated acts revealed important predictive value for predicting posttraumatic stress in this replication study. Nevertheless, traumatic events seem relevant for predicting appetitive aggression. This became particularly obvious in the current study. For psychotherapeutic interventions with individuals previously involved in violent conflicts it is imperative to abandon the dichotomous victim-perpetrator archetype. The symptoms of posttraumatic stress and heightened levels of aggression can be addressed and treated more effectively when all forms of exposure to violence-experienced, witnessed, and perpetrated-as well as the associated feelings are taken into consideration without judgment. Such an attempt has been made in Narrative Exposure Therapy for Forensic Offender Rehabilitation (FORNET; Elbert et al., 2012; Hermenau et al., 2013b; Crombach and Elbert, 2015; Köbach et al., in press). In 5-7 sessions, the therapist and the client intensively reflected on the most poignant incidents of violence (exposure in sensu) and framed crucial, transitory changes from combatant to civilian. FORNET successfully reduced posttraumatic stress (Hermenau et al., 2013b; Köbach et al., in press) and the number of violent offenses (Crombach and Elbert, 2015). Further research is required.

Furthermore, this study replicated the results that "participation in a massacre," "having mutilated someone," 
TABLE 1 | Thirty-six-question guide to the Replication Recipe (Brandt et al., 2014).

\section{THE NATURE OF THE EFFECT}

1 Verbal description of the effect I am trying to replicate:

2 It is important to replicate this effect because ...

3 The effect size of the effect I am trying to replicate is:

4 The confidence interval of the original effect is:

5 The sample size of the original effect is:

6 Where was the original study conducted? (e.g., lab, in the field, online)

7 What country/region was the original study conducted in?

8 What kind of sample did the original study use? (e.g., student, Mturk, representative)

9 Was the original study conducted with paper-and pencil surveys, on a computer, or something else?

\section{DESIGNING THE STUDY}

10 Are the original materials for the study available from the author?

11 I know that assumptions (e.g., about the meaning of the stimuli) in the original study will also hold in my replication because:

12 Location of the experimenter during data collection:

13 Experimenter knowledge of participant experimental condition:

14 Experimenter knowledge of overall hypotheses:

15 My target sample size is:

16 The rationale for my sample size is:

\section{DOCUMENTING DIFFERENCES BETWEEN THE ORIGINAL AND REPLICATION STUDY}

For each part of the study indicate whether the replication study is Exact, Close, or Conceptually Different

compared to the original study. Then, justify the rating

17 The similarities/differences in the instructions are:

18 The similarities/differences in the measures are:

19 The similarities/differences in the stimuli are:

20 The similarities/differences in the procedure are:

21 The similarities/differences in the location (e.g., lab vs. online; alone vs. in groups) are:

22 The similarities/differences in remuneration are:

23 The similarities/differences between participant populations are:

24 What differences between the original study and your study might be expected to influence the size and/or direction of the effect?

25 I have taken the following steps to test whether the differences listed in \#24 will influence the outcome of my replication attempt:

\section{ANALYSIS AND REPLICATION EVALUATION}

26 My exclusion criteria are (e.g., handling outliers, removing participants from analysis):

27 My analysis plan is (just if it differences from the original):

28 A successful replication is defined as:

\section{REGISTERING THE REPLICATION ATTEMPT}

29 The finalized materials, procedures, analysis plan, etc. of the replication are In the main article registered here:

\section{REPORTING THE REPLICATION}

30 The effect size of the replication is: (a) Cumulative lifetime perpetrated acts of violence are associated with higher levels of appetitive aggression.(b) Particularly, events that incorporate salient cues of violence have higher predictive importance for appetitive aggression

... the appealing aspect of violence is often neglected although it has an immense impact on (post-war) societies and mostly co-occurs with poor mental health

$\mathrm{n} / \mathrm{a}$; As in the original study we used RF-Cl. Outcome measures can be drawn from Figure 1 in the article

$\mathrm{n} / \mathrm{a}$

$N=95$

In the field

Democratic Republic of Congo, North Kivu, Goma

Demobilizing, male, adult, Congolese ex-combatants

The original study was conducted with paper-and pencil. The replication study was conducted with iPads

\section{On demand}

Yes.

On site

Interviewers did not know the hypothesis

Interviewers did not know the hypothesis

$\mathrm{n} / \mathrm{a}$

Interview capacity, time, availability of ex-combatants

[Exact]

[Close]; few events/acts were not asked in the replication study and vice versa. Outcome (AAS, PSS-I sum scores) was measured by exactly the same instruments $\mathrm{n} / \mathrm{a}$

[Close]; iPads were used documenting the answers in the replication study. The interview setting was the same, but in different countries

[Exact]

[Exact]; transport money was paid in the replication study; in the original study ex-combatants were on site and thus no transport necessary

[Close]; similarities: ex-combatants in both studies fought in one or more African civil wars with similar kinds of events and living conditions; differences: ex-combatants in DRC have been in their demobilization process, while those in Burundi had been demobilized on average 6 years ago

In the replication study participants had been demobilized for a longer period of time

$\mathrm{n} / \mathrm{a}$

Participants with missing(s) in the event list, PSS-I or AAS as well as participants who gave invalid answers were excluded from the analysis

$\mathrm{n} / \mathrm{a}$

(a) Similar pattern of variable importance (cvis) and (b) acceptable model fits 


\section{TABLE 1 | Continued}

31 The confidence interval of the replication effect size is:

32 The replication effect size [is/is not] (circle one) significantly different from the original effect size?

33 I judge the replication to be a(n) [success/informative failure to replicate/practical failure to replicate/inconclusive] (circle one) because:

34 Interested experts can obtain my data and syntax here:

35 All of the analyses were reported in the report or are available here:

36 The limitations of my replication study are: $\mathrm{n} / \mathrm{a}$

$\mathrm{n} / \mathrm{a}$

Success; The patterns of variance importances (cvis) are similar and the model fits acceptable

On demand

In the article. Further information about the Burundian sample are published in Nandi et al. (in press)

Few events were not asked in the replication study and vice versa and "having witnessed a massacre" - events/acts with very salient and predatory cues of violence (e.g., blood, screaming, suffering, etc.) - are important predictors for the level of appetitive aggression. In the present study, this was the case even years after demobilization! These events may deserve particular focus in psychotherapy.

The discrepancy in the time difference since demobilization in the current sample (6 years) in comparison to the Congolese sample in which the participants were interviewed during the demobilization process, suggests that the associations between perpetrated acts and appetitive aggression as well as traumatic events and posttraumatic stress remain stable over time; in fact, the patterns of variable importances are astonishingly similar, both for single specific event types/acts as well as the total exposure to different forms of violence (see Figure 1). The model fits were generally lower in the replication study.

This replication article has limitations. First, the earlier result indicating that the total number of lifetime traumatic event types and violent acts would predict PTSD better than specific event types was not replicated for both the level of appetitive aggression and posttraumatic stress. Further, the models were not exactly the same as were used in the original study, owed to the slightly varying event lists. Finally, it is noteworthy, that causal interpretations cannot be drawn given the crosssectional study design together with a rather descriptive statistical operationalization.

\section{CONCLUSION}

In conclusion, the results indicate that the perpetration of violent acts during war continuously shapes a perpetrator's perception of

\section{REFERENCES}

Anderson, C., and Bushman, B. (2002). Human aggression. Annu. Rev. Psychol. 53, 27-51. doi: 10.1146/annurev.psych.53.100901.135231

Brandt, M. J., IJzerman, H., Dijksterhuis, A., Farach, F. J., Geller, J., GinerSorolla, R., et al. (2014). The replication recipe: what makes for a convincing replication? J. Exp. Soc. Psychol. 50, 217-224. doi: 10.1016/j.jesp.2013. 10.005

Brewin, C. R., Gregory, J. D., Lipton, M., and Burgess, N. (2010). Intrusive images in psychological disorders: characteristics, neural mechanisms, and treatment implications. Psychol. Rev. 117, 210-232. doi: 10.1037/a0018113 and affiliation for violence. To create stable communities, secure family environments and healthy minds, evidence-based mental health care needs to abandon simplistic victim-perpetrator dichotomies and develop interventions that take the whole range of combat-related complications into account.

\section{AUTHOR CONTRIBUTIONS}

$\mathrm{CN}$ and $\mathrm{AC}$ performed the interviewer training and supervised the data collection. MB provided support on site. AK performed the data analysis and interpretation with support by BW and under the supervision of TE. AK drafted the paper, and CN, AC, and TE provided critical revisions. All of the authors approved the final version of the paper for submission.

\section{FUNDING}

VolkswagenStiftung und Deutsche Forschungsgesellschaft.

\section{ACKNOWLEDGMENTS}

We sincerely thank our Burundian partners, especially the University Lumière of Bujumbura, for their excellent research cooperation. We express our gratitude to the former combatants who participated in this study, the students of the University Lumière and our translators. We thank the Institute of Databases and Information Systems of University Ulm (Manfred Reichert and staff) for enabling electronic data collection. We are grateful to James Moran and Danie Meyer-Parlapanis who supported the interviews and provided valued suggestions in regard to writing.
Crombach, A., and Elbert, T. (2015). Controlling offensive behavior using narrative exposure therapy: a randomized controlled trial of former street children. Clin. Psychol. Sci. 3, 270-282. doi: 10.1177/2167702614534239

Crombach, A., Weierstall, R., Hecker, T., Schalinski, I., and Elbert, T. (2013). Social status and the desire to resort to violence: using the example of Uganda's former child soldiers. J. Aggress. Maltreat. Trauma 22, 559-575. doi: 10.1080/10926771.2013.785458

Dohrenwend, B. P., Turner, B. J., Turse, N. A., Adams, B. G., Koenen, K. C., and Marshall, R. (2006). The psychological risks of Vietnam for U.S. Veterans: a revisit with new data and methods. Science 313, 979-982. doi: $10.1126 /$ science. 1128944 
Ehlers, A., and Clark, D. M. (2000). A cognitive model of posttraumatic stress disorder. Behav. Res. Ther. 38, 319-345. doi: 10.1016/S0005-7967(99)00123-0

Elbert, T., Hermenau, K., Hecker, T., Weierstall, R., and Schauer, M. (2012). "FORNET: Behandlung von traumatisierten und nicht-traumatisierten Gewalttätern mittels Narrativer Expositionstherapie," in Interventionen bei Gewalt- und Sexualstraftätern: Risko-Management, Methoden und Konzepte der forensischen Therapie, eds J. Endras, A. Rossegger, F. Urbaniok, and B. Borchard (Berlin: Medizinisch Wissenschaftliche Verlagsgesellschaft), 255-276.

Elbert, T., Schauer, M., and Neuner, F. (2015). "Narrative Exposure Therapy (NET): reorganizing memories of traumatic stress, fear and violence," in Evidence Based Treatments for Trauma-Related Psychological Disorders: A Practical Guide for Clinicians, eds U. Schnyder and M. Cloitre (Heidelberg; New York, NY; London: Springer), 229-253. doi: 10.1007/978-3-319-07109-1

Elbert, T., Weierstall, R., and Schauer, M. (2010). Fascination violence: on mind and brain of man hunters. Eur. Arch. Psychiatry Clin. Neurosci. 260(Suppl. 2), 100-105. doi: 10.1007/s00406-010-0144-8

Ertl, V., Pfeiffer, A., Saile, R., Schauer, E., Elbert, T., and Neuner, F. (2010). Validation of a mental health assessment in an African conflict population. Psychol. Assess. 22, 318-324. doi: 10.1037/a0018810

Foa, E. B., Riggs, D. S., Dancu, C. V., and Rothbaum, B. O. (1993). Reliability and validity of a brief instrument for assessing post-traumatic stress disorder. $J$. Trauma. Stress 6, 459-473. doi: 10.1002/jts.2490060405

Foa, E. B., and Tolin, D. F. (2000). Comparison of the PTSD symptom scaleinterview version and the clinician-administered PTSD Scale. J. Trauma. stress 13, 181-191. doi: 10.1023/A:1007781909213

Grömping, U. (2009). Variable importance assessment in regression: linear regression versus random forest. Am. Stat. 63, 308-319. doi: 10.1198/tast.2009.08199

Grossman, D. (1995). On Killing: The Psychological Cost of Learning to Kill in War and Society. Boston: Little, Brown and Co.

Hecker, T., Hermenau, K., Maedl, A., Elbert, T., and Schauer, M. (2012). Appetitive aggression in former combatants-derived from the ongoing conflict in DR Congo. Int. J. Law Psychiatry 35, 244-249. doi: 10.1016/j.ijlp.2012.02.016

Hecker, T., Hermenau, K., Maedl, A., Schauer, M., and Elbert, T. (2013). Aggression inoculates against PTSD symptom severity-insights from armed groups in the eastern DR Congo. Eur. J. Psychotraumatol. 4, 1-9. doi: 10.3402/ejpt.v4i0.20070

Hermenau, K., Hecker, T., Mädl, A., Schauer, M., and Elbert, T. (2013a). Growing up in armed groups: trauma and aggression among child soldiers in DR Congo. Eur. J. Psychotraumatol. 1, 1-9. doi: 10.3402/ejpt.v4i0.20070

Hermenau, K., Hecker, T., Schaal, S., Mädl, A., and Elbert, T. (2013b). Addressing post-traumatic stress and aggression by means of narrative exposure: a randomized controlled trial with ex-combatants in the eastern DRC. J. Aggress. Maltreat. Trauma 22, 916-934. doi: 10.1080/10926771.2013.824057

Hoge, C. W., Auchterlonie, J. L., and Milliken, C. S. (2006). Mental health problems, use of mental health services, and attrition from military service after returning from deployment to Iraq or Afghanistan. JAMA 295, 1023-1032. doi: 10.1001/jama.295.9.1023

Hothorn, T., Bühlmann, P., Dudoit, S., Molinaro, A., and van der Laan, M. J. (2006a). Survival ensembles. Biostatistics 7, 355-373. doi: 10.1093/biostatistics/kxj011

Hothorn, T., Hornik, K., and Zeileis, A. (2006b). Unbiased recursive partitioning: a conditional inference framework. J. Comput. Graph. Stat. 15, 651-674. doi: 10.1198/106186006X133933

Köbach, A., Schaal, S., and Elbert, T. (2014). Combat high or traumatic stress: violent offending is associated with appetitive aggression but not with symptoms of traumatic stress. Front. Psychol.. 5:1518. doi: 10.3389/fpsyg.2014.01518

Köbach, A., Schaal, S., Hecker, T., and Elbert, T. (in press). Psychotherapeutic intervention in the demobilization process: addressing combat-related mental injuries with narrative exposure in a first and second dissemination stage. Clin. Psychol. Psychother.

Komarovskaya, I., Maguen, S., McCaslin, S. E., Metzler, T. J., Madan, A., Brown, A. D., et al. (2011). The impact of killing and injuring others on mental health symptoms among police officers. J. Psychiatr. Res. 45, 1332-1336. doi: 10.1016/j.jpsychires.2011.05.004

MacNair, R. M. (2002). Perpetration-induced traumatic stress in combat veterans. Peace Conflic 8, 63-72. doi: 10.1207/S15327949PAC0801_6
Maguen, S., Lucenko, B. A., Reger, M. A., Gahm, G. A., Litz, B. T., Seal, K. H., et al. (2010). The impact of reported direct and indirect killing on mental health symptoms in Iraq war veterans. J. Traumat. stress 23, 86-90. doi: $10.1002 /$ jts.20434

Maguen, S., Metzler, T. J., Litz, B. T., Seal, K. H., Knight, S. J., and Marmar, C. R. (2009). The impact of killing in war on mental health symptoms and related functioning. J. Traumat. Stress 22, 435-443. doi: 10.1002/jts. 20451

Moran, J. K., Weierstall, R., and Elbert, T. (2014). Differences in brain circuitry for appetitive and reactive aggression as revealed by realistic auditory scriptsNo. Front. Behav. Neurosci. 8:425. doi: 10.3389/fnbeh.2014.00425

Morland, L. A., Love, A. R., Mackintosh, M.-A., Greene, C. J., and Rosen, C. S. (2012). Treating anger and aggression in military populations: research updates and clinical implications. Clin. Psychol. 19, 305-322. doi: 10.1111/cpsp. 12007

Nandi, C., Crombach, A., Bambonye, M., Elbert, T., and Weierstall, R. (in press). Appetitive Aggression and Its Relation to Posttraumatic Stress in Burundian Ex-Combatants. J. Peace Psychol. doi: 10.1037/pac0000138

Nell, V. (2006). Cruelty's rewards: the gratifications of perpetrators and spectators. Behav. Brain Sci. 29, 211-224; discussion 224-257. doi: $10.1017 / \mathrm{s} 0140525 \times 06009058$

Odenwald, M., Hinkel, H., Schauer, E., Schauer, M., Elbert, T., Neuner, F., et al. (2009). Use of khat and posttraumatic stress disorder as risk factors for psychotic symptoms: a study of Somali combatants. Soc. Sci. Med. 69, 10401048. doi: 10.1016/j.socscimed.2009.07.020

Powers, M. B., Halpern, J. M., Ferenschak, M. P., Gillihan, S. J., and Foa, E. B. (2010). A meta-analytic review of prolonged exposure for posttraumatic stress disorder. Clin. Psychol. Rev. 30, 635-641. doi: 10.1016/j.cpr.2010. 04.007

Priebe, S., Jankovic Gavrilovic, J., Bremner, S., Ajdukovic, D., Franciskovic, T., Galeazzi, G. M., et al. (2013). Psychological symptoms as longterm consequences of war experiences. Psychopathology 46, 45-54. doi: $10.1159 / 000338640$

Robjant, K., and Fazel, M. (2010). The emerging evidence for Narrative Exposure Therapy: a review. Clin. Psychol. Rev. 30, 1030-1039. doi: 10.1016/j.cpr.2010.07.004

Schaal, S., Weierstall, R., Dusingizemungu, J.-P., and Elbert, T. (2012). Mental health 15 years after the killings in Rwanda: imprisoned perpetrators of the genocide against the Tutsi versus a community sample of survivors. J. Traumat. Stress 25, 446-453. doi: $10.1002 /$ jts. 21728

Schauer, M., Neuner, F., and Elbert, T. (2011). Narrative Exposure Therapy (NET): A Short-Term Intervention for Traumatic Stress Disorders, 2 Edn. Cambridge/Göttingen: Hogrefe \& Huber Publishers.

Schauer, M., Neuner, F., Karunakara, U. K., Klaschik, C., Robert, C., and Elbert, T. (2003). PTSD and the 'Building Block' Effect of Psychological Trauma Among West Nile Africans. Konstanz: Bibliothek der Universität Konstanz.

Steenkamp, M. M., and Litz, B. T. (2013). Psychotherapy for military-related posttraumatic stress disorder: review of the evidence. Clin. Psychol. Rev. 33, 45-53. doi: 10.1016/j.cpr.2012.10.002

Stenmark, H. k., Guzey, I. C., Elbert, T., and Holen, A. (2014). Gender and offender status predicting treatment success in refugees and asylum seekers with PTSD. Eur. J. Psychotraumatol. 5, 1-7. doi: 10.3402/ejpt.v5.20803

Strobl, C. (2008). Statistical Issues in Machine Learning: Towards Reliable Split Selection and Variable Importance Measures. PhD thesis, Universitaet Munich, Maximilianstrasse.

Strobl, C., Boulesteix, A.-L., Kneib, T., Augustin, T., and Zeileis, A. (2008). Conditional variable importance for random forests. BMC Bioinform. 9:307. doi: 10.1186/1471-2105-9-307

Strobl, C., Hothorn, T., and Zeileis, A. (2009a). Party on! A new, conditional variable-importance measure for random foerest available in the party package. RJ. 1, 14-17.

Strobl, C., Malley, J., and Tutz, G. (2009b). An introduction to recursive partitioning: rationale, application and characteristics of classification and regression trees, bagging and random forests. Psychol. Methods 14, 323-348. doi: $10.1037 / \mathrm{a} 0016973$

Van Winkle, E. P. and Safer, M. A. (2011). Killing versus witnessing in combat trauma and reports of PTSD symptoms and domestic violence. J. Traumat. Stress $24,107-110$. doi: $10.1002 /$ jts.20614 
Vitiello, B., and Stoff, D. M. (1997). Subtypes of aggression and their relevance to child psychiatry. J. Am. Acad. Child Adolesc. Psychiatry 36, 307-315. doi: 10.1097/00004583-199703000-00008

Weierstall, R., Castellanos, C. P., Neuner, F., and Elbert, T. (2013a). Relations among appetitive aggression, post-traumatic stress and motives for demobilization: a study in former Colombian combatants. Conflict Health 7, 9. doi: 10.1186/1752-1505-7-9

Weierstall, R., and Elbert, T. (2011). The Appetitive Aggression Scale-development of an instrument for the assessment of human's attraction to violence. Eur. J. Psychotraumatol. 2, 1-11. doi: 10.3402/ejpt.v2i0.8430

Weierstall, R., Hinsberger, M., Kaminer, D., Holtzhausen, L., Madikane, S., and Elbert, T. (2013b). Appetitive aggression and adaptation to a violent environment among youth offenders. Peace Conflict 19, 138-149. doi: $10.1037 / \mathrm{a} 0032489$

Weierstall, R., Huth, S., Knecht, J., Nandi, C., and Elbert, T. (2012a). Appetitive aggression as a resilience factor against trauma disorders: appetitive aggression and PTSD in German World War II veterans. PLoS ONE 7:50891. doi: 10.1371/journal.pone.0050891

Weierstall, R., Schaal, S., Schalinski, I., Dusingizemungu, J.-P., and Elbert, T. (2011). The thrill of being violent as an antidote to posttraumatic stress disorder in Rwandese genocide perpetrators. Eur. J. Psychotraumatol. 2, 1-8. doi: 10.3402/ejpt.v2i0.6345

Weierstall, R., Schalinski, I., Crombach, A., Hecker, T., and Elbert, T. (2012b). When combat prevents PTSD symptoms-results from a survey with former child soldiers in Northern Uganda. BMC Psychiatry 12:41. doi: 10.1186/1471244X-12-41

Westner, B. (2013). Fokale Dystonie bei Musikern: Prädiktion für den Krankheitsverlauf. Konstanz: University of Konstanz.

Conflict of Interest Statement: The authors declare that the research was conducted in the absence of any commercial or financial relationships that could be construed as a potential conflict of interest.

Copyright (c) 2015 Köbach, Nandi, Crombach, Bambonyé, Westner and Elbert. This is an open-access article distributed under the terms of the Creative Commons Attribution License (CC BY). The use, distribution or reproduction in other forums is permitted, provided the original author(s) or licensor are credited and that the original publication in this journal is cited, in accordance with accepted academic practice. No use, distribution or reproduction is permitted which does not comply with these terms. 